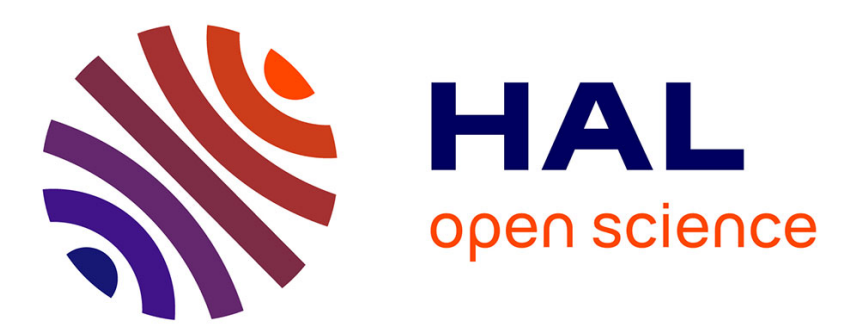

\title{
Development of a Time-Of-Flight Compton Camera for Online Control of Ion therapy
}

\author{
J.-L. Ley, C. Abellan, J.-P. Cachemiche, M. Dahoumane, D. Dauvergne, N.
} Freud, Baptiste Joly, J. Krimmer, Loïc Lestand, Jean Michel Létang, et al.

\section{- To cite this version:}

J.-L. Ley, C. Abellan, J.-P. Cachemiche, M. Dahoumane, D. Dauvergne, et al.. Development of a Time-Of-Flight Compton Camera for Online Control of Ion therapy. ICTR-PHE 2014, Feb 2014, Genève, Switzerland. hal-00945490

\author{
HAL Id: hal-00945490 \\ https://hal.science/hal-00945490
}

Submitted on 14 Nov 2018

HAL is a multi-disciplinary open access archive for the deposit and dissemination of scientific research documents, whether they are published or not. The documents may come from teaching and research institutions in France or abroad, or from public or private research centers.
L'archive ouverte pluridisciplinaire HAL, est destinée au dépôt et à la diffusion de documents scientifiques de niveau recherche, publiés ou non, émanant des établissements d'enseignement et de recherche français ou étrangers, des laboratoires publics ou privés. 


\title{
DEVELOPMENT OF A TIME-OF-FLIGHT COMPTON CAMERA FOR ONLINE CONTROL OF ION THERAPY
}

\section{COMPTON CAMERA}

\section{PURPOSE}

The aim of irradiation monitoring during a treatment in ion therapy is to control in real time the agreement between the delvered dose and the planded reatment. In fact, the discrepancles might come from uncertainties such as the posil dille potential high efficiency to detect prompt gamma rays [1,2,3,4]. The present work aims at discussing the clinica applicability of a Compton camera design by means of Monte Carlo simulations for proton and carbon ion therapy.

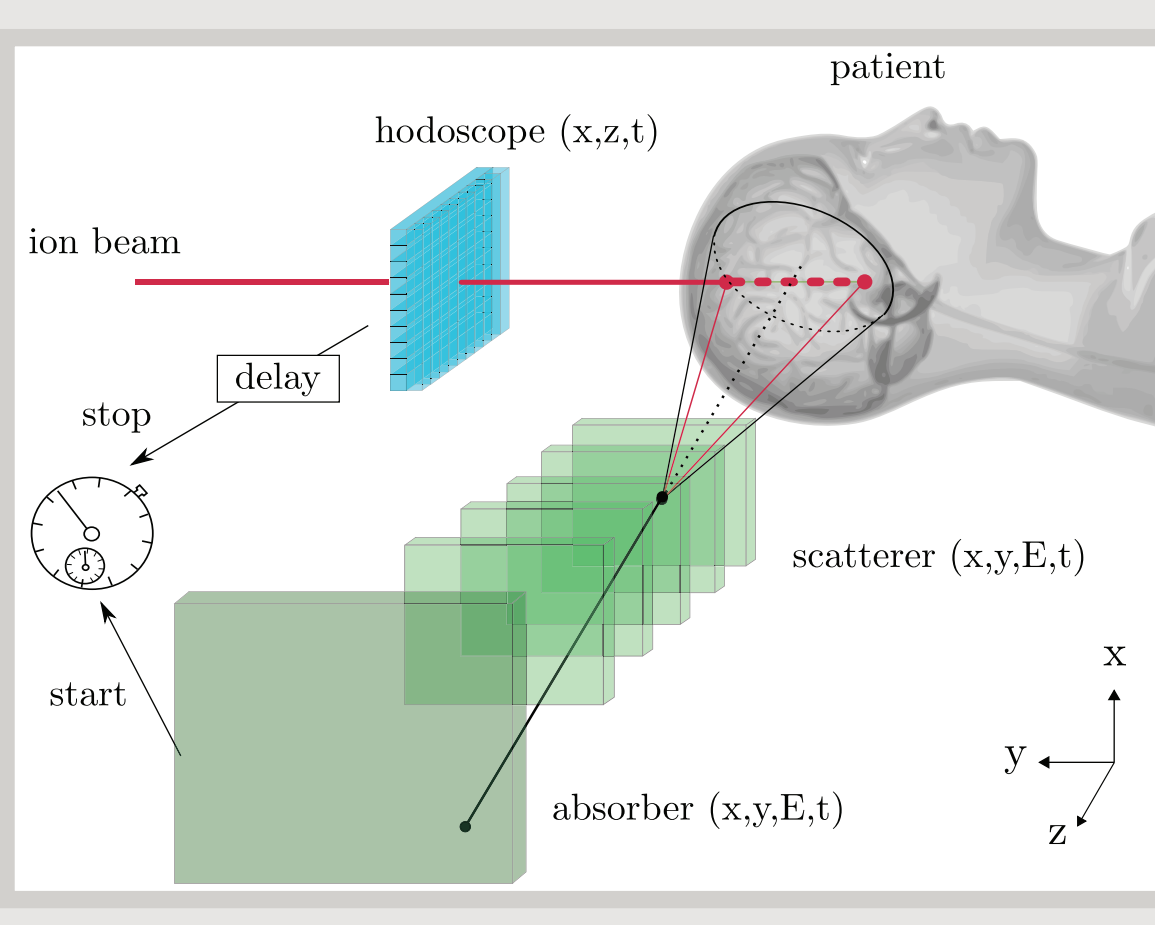

Fig. 1.

Configuration of the monitoring system: the prompt gamma-ray emission Compton the the Compton cone is reconstructed with the camera. Time of flight (TOF) (with an appropriate delay) are performed. [5]

\section{SIMULATIONS GEANT4.9.6}

\section{KEY POINTS}

- Monte-Carlo simulation: Geant4.9.6

- Use the standard electromagnetic processes and the Binary Cascade model for hadrons - Taking account of the Doppler broadening and polarizatic $0.1 \mathrm{~mm}$ in PMMA and $1 \mathrm{~mm}$ in the detectors

\begin{tabular}{|c|c|c|c|}
\hline & Protons & Carbon ions & \multirow{4}{*}{$\begin{array}{l}\text { Table 1. Parameters usece } \\
\text { for the simulation of the } \\
\text { Compton camera. }\end{array}$} \\
\hline Number & $10^{8}$ & $4 \times 10^{7}$ & \\
\hline Energy & $160 \mathrm{MeV}$ & $305 \mathrm{MeV} / \mathrm{u}$ & \\
\hline Bragg peak position & \multicolumn{2}{|c|}{$15.5 \mathrm{~cm}$} & \\
\hline
\end{tabular}

\begin{tabular}{|l|l|l|l|l}
\hline Resolution (FWHM) @ 1 MeV & BGO & Si & Table 2. Realistic resolutions \\
\hline
\end{tabular} \begin{tabular}{|l|c|c|c|c|}
\hline Spatial [mm] & 5 & 0.9 & $\begin{array}{l}\text { the detectors. The energy } \\
\text { thesolution for the silicon is } \\
\text { rest }\end{array}$ \\
\hline
\end{tabular} Energy [\%]

Timing [ns]

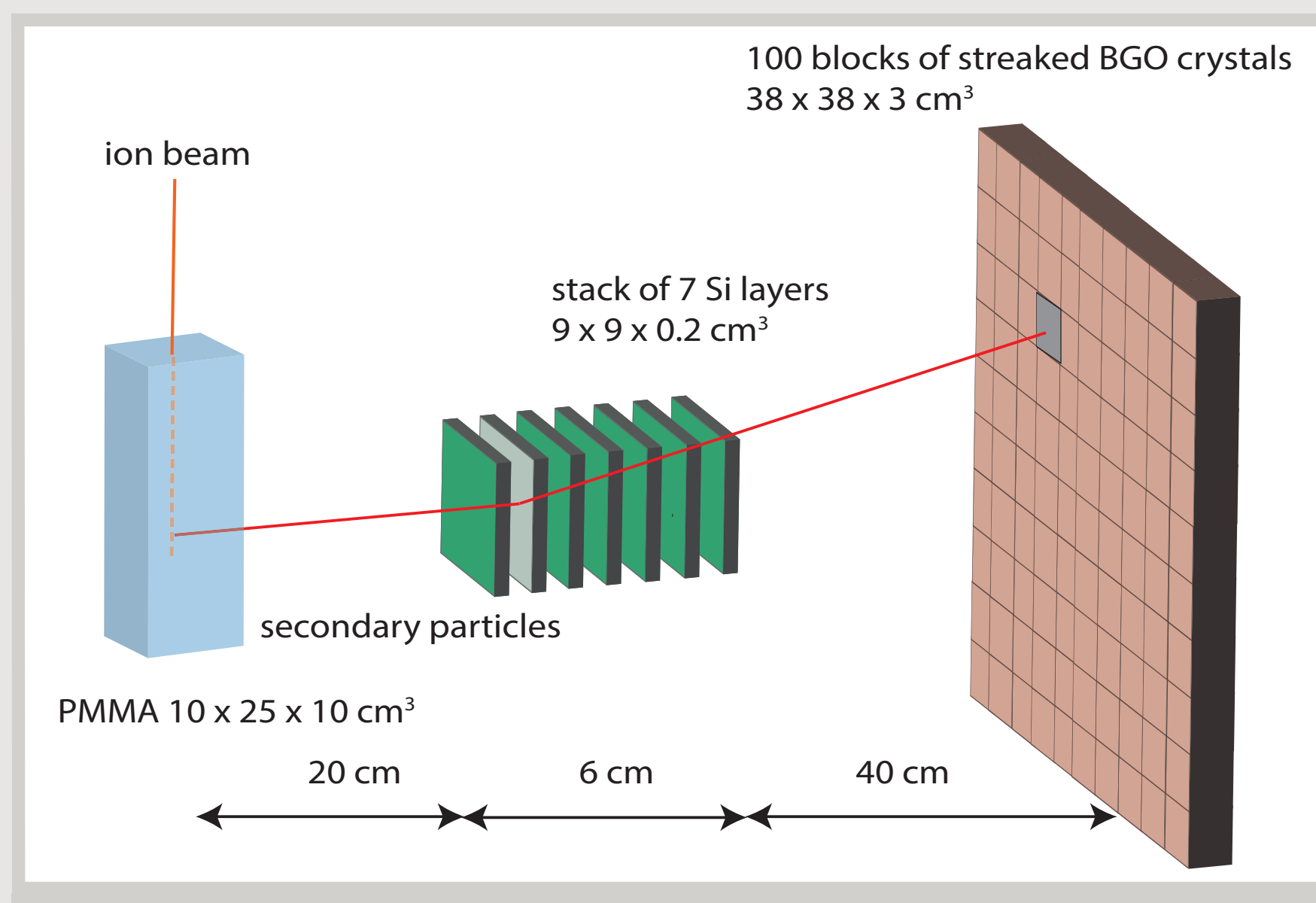

Fig. 2. Diagram of the simulation setup.

\section{DATA TREATMENT} A beam time structure is modeled and applied to the simulation data in order to estimate the coincidence
rate (true/random) for a clinical application of the Compton camera. The treatment is done for protons

CLINICAL CHARACTERISTICS

BEAM STRUCTURE

\begin{tabular}{|c|c|c|}
\hline & Protons & Carbon ions \\
\hline Facility & Cyclotron C230 IBA & Synchroton at HIT \\
\hline Clinical intensity & $2 \times 10^{10} \mathrm{p} / \mathrm{s}$ & $5 \times 10^{7}$ ions/s \\
\hline Energy & $160 \mathrm{MeV}$ & $305 \mathrm{MeV} / \mathrm{u}$ \\
\hline Bunch time [ns] & 3.2 & 30 \\
\hline Period [ns] & 9.4 & 170 \\
\hline Particles / bunch & 217 & 9 \\
\hline Coincidence window [ns] & 40 & 40 \\
\hline
\end{tabular}

Table 3. Characteristics of clinical beams using protons and carbon ions. Each particle is treated
as an individual story in the simulation Geant4. The beam time strucure is modeled in the simulation

\section{RESULTS}

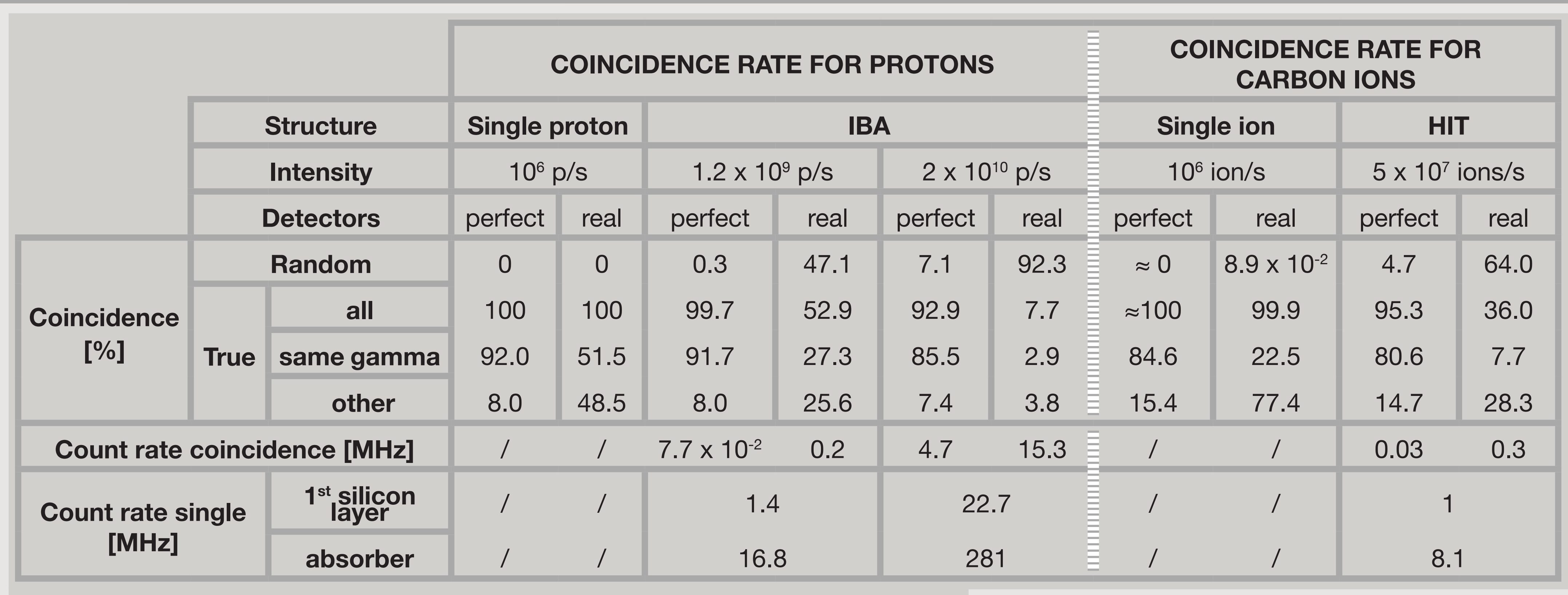

\author{
COINCIDENCE \\ Coincidence: one energy deposit in the BGO absorber and one (only one) energy deposit in a Si of the scattere \\ Random coincidence: the energy deposits in the scatterer and the absorber are induced by radiations coming \\ True coincidence: the energy deposits in the scat \\ Truations coming from a single incident particle. \\ - same gamma: a true coincidence coming from the same gamma in Si and BGO.
- other: the other possibilities for a true coincidence are : \\ two different kinds of particles \\ - same particle but different than gamma
}

RECONSTRUCTION METHOD

The reconstruction method chosen to get the falloff position is the line-cone method. This method calculates the intersection between a line (trajectory of the incident particle on the target) and a cone (the Compton cone): there are two solutions. Some coincidences have no solutions with this method. Therefore, there is a difference between the coincidence rates in table 4 and the number of reconstructed coincidences due to the solutions allowed by

the line-cone method. There are three times less events in the
only the closest solution to the falloff is taken into account.

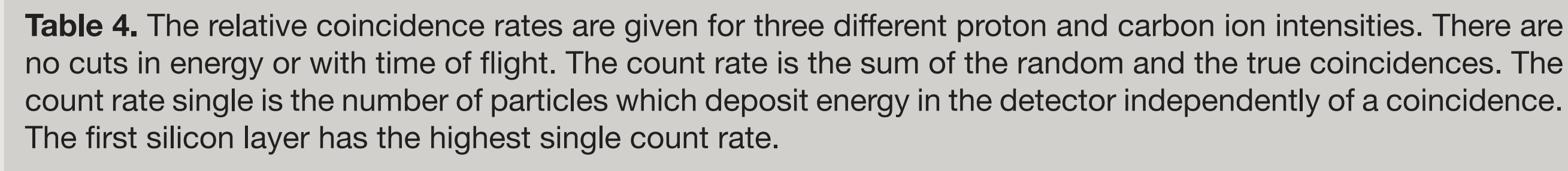

DEFINITIONS

STRUCTURE

Single particle: One particle is run each microsecond

IBA or HIT: Application of the specific time beam structure

DETECTORS

Perfect: no timing resolution is applied. The time window defined to

detect a coincidence is the time for a photon to fly from the silicon layer

Real: a realistic timing resolution is applied to the detectors (table 3) and the
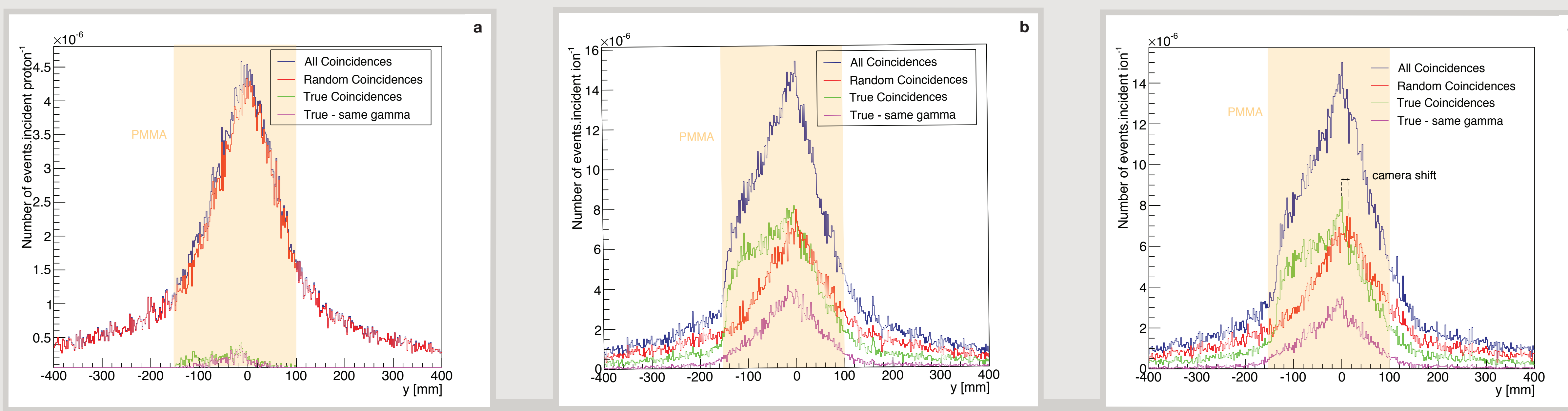

Fig. 4. Reconstructed profile in the case of pron

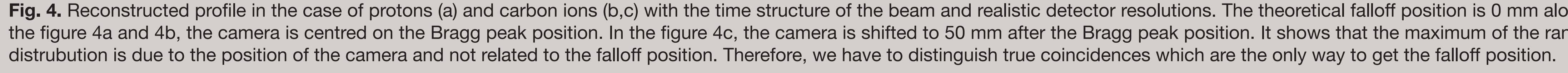

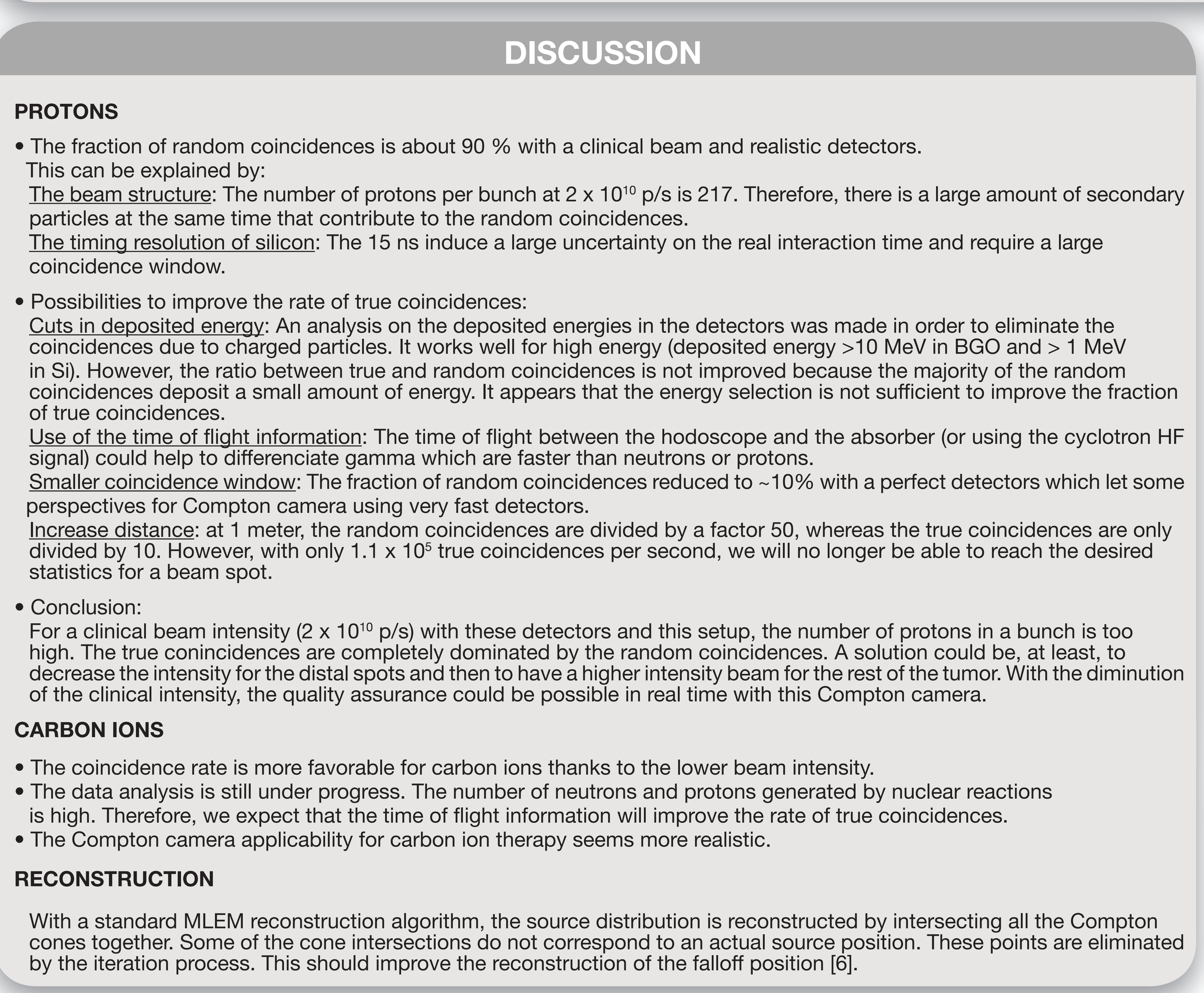

\section{PROTOTYPE DEVELOPMENT}

THERE ARE THREE PARTS:

1. Hodoscope $\rightarrow$ Poster 32 (J. Krimmer)

- Scintillating square fibers: $140 \times 1 \times 1 \mathrm{~mm}$

- Number of fibers: $2 \times 128$ 128

- Timing resolution: $1 \mathrm{~ns}$

2. Scatterer (Double-sided silicon strip detector)

- Number of layers: 7

- Dimensions: $90 \times 90 \times 2 \mathrm{~mm}$

- Number of strips: $2 \times 64$

Expected performances

- Spatial resolution: $1 \mathrm{~mm}$

3. Absorber (streaked BGO)

- Dimensions: $380 \times 355 \times 30 \mathrm{~mm}^{3}$

- 4 PMTs per block

- Timing resolution: $3 \mathrm{~ns}$

4. $\mu$ TCA acquisition system $\rightarrow$ Poster 3 (C. Abellan)

- Communication between the $\mu \mathrm{TCA}$ and the

acquisition computer thanks to a gigabit ethernet link.
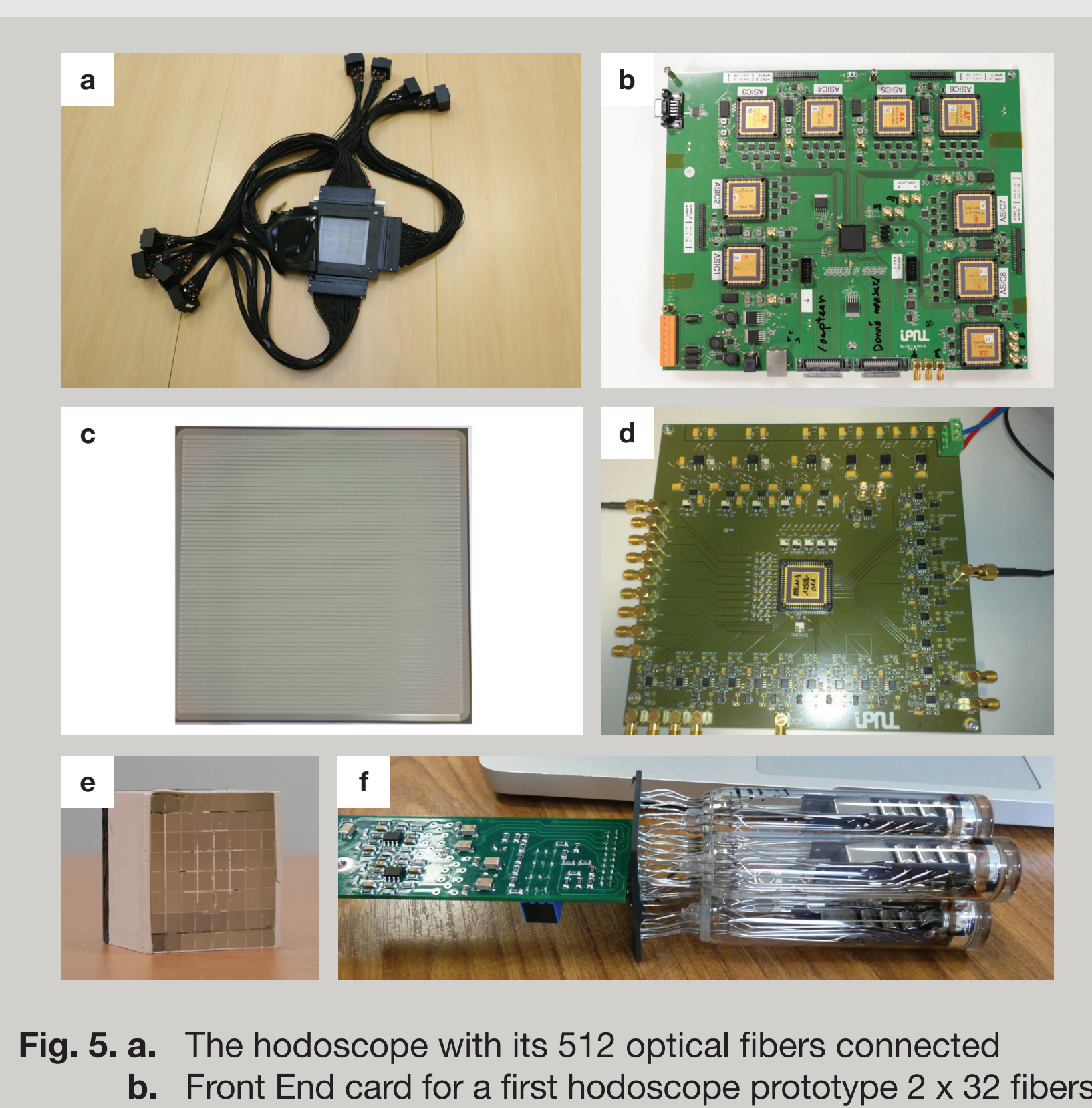

c. Double-sided silicon strip detector
d. First prototype of a ASCC for the DSSD's front end

e. BGO block 96 blocks compose the abs
f. Each block is connected to 4 PMTs

\section{REFERENCES \\ CONTACT}

[1] S.W. Peterson et al., Phys. Med. Biol. 55 (2010) 6841-6856

[2] G. Llosa et al., NIMA 695(2012)105-108

[3] T. Kormoll et al., IEEE-TNS (2011) 3484 - 3487

[4] S. Kurosawa et al., Current Applied Physics 12 (2012) 364-368 [5] M.-H. Richard et al, IEEE-NSS/MIC (2011) 3496-3500 